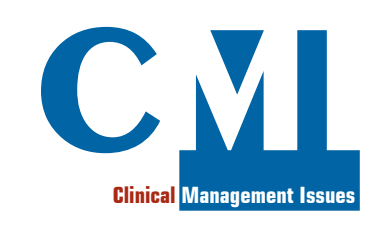

\title{
Editorial Staff Disclosure (2018)
}

Laura Fascio Pecetto is the Managing Editor of CMI journal. She declares to have no personal conflicts of interests. She works for SEEd Medical Publishers, that in 2018 has worked with AdRes Srl, Amgen Srl, Bayer SpA, Biogen Italia Srl, Clicon Srl, CSL Behring SpA, Gilead Sciences Srl, HPS-Health Publishing \& Services Srl, ICON Clinical Research, Roche SpA.

Rossella Iannone is Editor of CMI journal. She declares to have no personal conflicts of interests. She works for SEEd Medical Publishers, that in 2018 has worked with AdRes Srl, Amgen Srl, Bayer SpA, Biogen Italia Srl, Clicon Srl, CSL Behring SpA, Gilead Sciences Srl, HPS-Health Publishing \& Services Srl, ICON Clinical Research, Roche SpA.

Enzo Cappelluti is the Layout Editor of CMI journal. He declares to have no personal conflicts of interests. He works for SEEd Medical Publishers, that in 2018 has worked with AdRes Srl, Amgen Srl, Bayer SpA, Biogen Italia Srl, Clicon Srl, CSL Behring SpA, Gilead Sciences Srl,HPS-Health Publishing \& Services Srl,ICON Clinical Research, Roche SpA. 